\title{
Unknown disturbance estimation for vibration systems using distributed piezoelectric sensors
}

\author{
Bin-Yi Wu ${ }^{1}$, Xian-Sheng Qin ${ }^{1}$, Shun-Qi Zhang ${ }^{2,3,{ }^{*}}$, Jing Bai ${ }^{1}$, Ting Xue ${ }^{1,4}$, and Rüdiger Schmidt ${ }^{5}$ \\ ${ }^{1}$ School of Mechanical Engineering, Northwestern Polytechnical University, 710072 Xi'an, PR China \\ 2 School of Mechatronic Engineering and Automation, Shanghai University, 99 Shangda Road, 200444 Shanghai, PR China \\ ${ }^{3}$ State Key Laboratory of Structural Analysis for Industrial Equipment, Dalian University of Technology, 116024 Dalian, \\ PR China \\ ${ }^{4}$ School of Mechanical Engineering, Xi'an University of Architecture and Technology, 710055 Xi'an, PR China \\ ${ }^{5}$ Institute of Structural Mechanics and Lightweight Design, RWTH Aachen University, 52062 Aachen, Germany
}

Received: 3 January 2017 / Accepted: 31 July 2017

\begin{abstract}
Vibration is usually caused by external disturbances, which may lead to structural damage. Vibrations can be significantly suppressed by taking disturbances into account. However, in many cases disturbances are unknown or difficult to be measured directly. In order to estimate external unknown disturbances, this article develops a proportional-integral (PI) disturbance observer with measurement noises for smart structures using multiple distributed piezoelectric sensors. For simulation purpose, a dynamic finite element model of piezoelectric bonded smart structure is presented. This disturbance observation method is validated by estimating various kinds of unknown disturbances using piezoelectric measurements. Furthermore, the measurement numbers and the position of measurements are investigated.
\end{abstract}

Keywords: Disturbance observation / proportional-integral observer / smart structures / distributed piezoelectric sensors

\section{Introduction}

In many cases, disturbances acting on structures cannot be measured directly due to complexity of the working environment $[1,2]$. However, disturbance is the major influence in a vibration system. If an unknown disturbance can be reconstructed, it is possible and easy to compensate by a feedback controller using appropriate control strategies [3]. Therefore, it is important to estimate external unknown disturbances for suppression of a vibration system.

Disturbance estimation, also known as loads identification, is used for solving problems of location and identification of excitation sources [4]. There are two main loads identification methods, namely, frequency domain method and time domain method [5]. The frequency domain method based on a linear model was first proposed by Barlett and Flannelly [6], and later developed by Hillary and Ewins [7] and Karlsson [8]. Although the development of the theory of frequency domain method is relatively mature, certainly there are some restrictions

\footnotetext{
* e-mail: zhangsq@shu.edu.cn
}

in this method, such as only fit for static and stationary loads [9].

Compared to the frequency-domain methods, timedomain methods can identify various types of loads including nonstationary ones, and the identified results have clear physical meaning. As a result, time-domain methods have good engineering applications prospect. Desnahgeer and Snoeys [10] and Ory et al. [11] developed dynamic load identification methods for discrete systems based on modal coordinate transformation in time domain. Force reconstruction is still ill-posed due to the inversion process and the white noise in measurement process. The regularization technique is utilized to deal with the issue in recent years and make positive progress. Jacquelin et al. [12] used timedomain deconvolution for force reconstruction and investigated regularization method of a deconvolution problem. An inverse system method for dynamic load identification was developed by Inoue et al. [13] and Kammer [14]. The inverse system method obtains an inverse model and directly computes the load. But in some cases, it is very difficult to find an inverse model of a system, which limits its application. However, several methods mentioned earlier require that the number of measuring points should be no less than the mode number, which is impossible in many real 
applications. In order to overcome the problem, Müller [15], Hou et al. [16], Söffker et al. [17] and Krajcin and Söffker [18] developed a proportional-integral (PI) observer to estimate unknown disturbances for vibration systems. This PI observer does not need to install the number of measurements as many as the number of modes. It only requires that the number of measurements is no less than the number of unknown disturbances [19]. Later, Zhang et al. [20,21] extended the PI observer to a generalized PI (GPI) observer for high-frequency disturbances.

Most of the above studies of disturbance estimation used various measurements, e.g., displacement, velocity or acceleration, which require specific sensors and installation spaces. With the development in material sciences, structures integrated with smart materials, like piezoelectric materials, magnetostrictive materials, known as smart structures, are frequently used in research and industrial engineering for vibration control, health monitoring and so on. In such kinds of structures, smart materials are highly integrated in the host structures acting as sensors $[22,23]$ or actuators [24]. Using the beneficial properties from smart structures, distributed piezoelectric sensors are used for boundary force measurements in Euler-Bernoulli beams by Chesne and Pezerat [25]. Furthermore, Zhang et al. [20,21] used piezoelectric sensors for unknown disturbance estimation of smart structures.

However, most disturbance estimation methods seldom considered the effects of the measurement noises, which always exist in real applications. To further improve the dynamic performance of disturbance observation system, the aim of this article is to extend the theory for estimation of unknown disturbances with measurement noises using multiple distributed piezoelectric sensors. A Kalman filter is employed for observer gain design and compared with the method proposed by Zhang et al. [20,21]. Afterward, the influence of measurement numbers and positions in estimation process is investigated by simulations. In general, the article is organized as follows: a general unknown disturbance observation model based on a linear state space model is developed in Section 2, Section 3 develops a dynamic finite element (FE) model of smart structure integrated with multipiezoelectric patches, which is followed by numerical simulations and analysis in Section 4, finally, conclusions and discussions are drawn in Section 5.

\section{Estimation of external unknown disturbances}

\subsection{General control system}

A time-continuous state-space model of a general system usually contains state differential equation (1) and output equation (2) as

$$
\begin{gathered}
\dot{x}=A x, \\
y=C x+n .
\end{gathered}
$$

Here, $A$ and $C$ are the system matrix and the output matrix. Additionally, $x$ is the state variable, $y$ is the sensor output signal, $n$ is the white Gaussian measurement noise with the variance matrix $R_{N}$. Considering the influence of external unknown disturbances, equation (1) can be expressed as follows [15]:

$$
\dot{x}=A x+N f .
$$

Here $f$ is the unknown external disturbance vector and $N$ is disturbance influence matrix.

\subsection{Extended system and extended observer system}

\subsubsection{Extended system}

Fourier series is commonly used to realize the linear formulation of the unknown disturbances, which is an expansion of a periodic function $f(t)$ in terms of an infinite sum of sines and cosines. So the components of an unknown disturbance vector can be expressed as

$$
f(t)=a_{0} / 2+\sum_{n=1}^{\infty}\left(a_{n} \cos n \omega t+b_{n} \sin n \omega t\right)
$$

Here, $\omega$ denotes the angular frequency of sine or cosine base functions.

The disturbance vector $f(t)$ can be expressed as a step function, only retaining the constant term of Fourier series. Any unknown disturbance can be approximated by $[16,20]$

$$
\begin{gathered}
f(t) \cong H v(t), \\
\dot{v}(t)=V v(t) .
\end{gathered}
$$

Here, $H$ and $V$ denote the output and system matrices of the fictitious model of disturbances. Because of using step function as basis function for any unknown disturbances, $H$ and $V$ matrices are respectively equal to identity and zero matrices, which results in (PI) observer $[16,20]$.

Substituting equations (5) and (6) into equations (2) and (3) and using a new state vector $x_{e}=\left\{\begin{array}{l}x \\ v\end{array}\right\}$, a state space model of an extended system including disturbances can be expressed as

$$
\begin{gathered}
\dot{x}_{e}=A_{e} x_{e}, \\
y=C_{e} x_{e}+n .
\end{gathered}
$$

Here, $A_{e}$ and $C_{e}$ are the system matrix and the output matrix of the extended system, which can be obtained as $[16]$

$$
\begin{gathered}
A_{e}=\left[\begin{array}{ll}
A & N H \\
0 & V
\end{array}\right], \\
C_{e}=\left[\begin{array}{ll}
C & 0
\end{array}\right] .
\end{gathered}
$$

\subsubsection{Extended observer system}

Constructing an estimated state vector $\hat{x}_{e}$ that minimizes the steady-state error covariance, the state space model of 
an extended observer system can be described as

$$
\begin{gathered}
\dot{\hat{x}}_{e}=A_{e} \hat{x}_{e}+L(y-\hat{y}), \\
\hat{y}=C_{e} \hat{x}_{e} .
\end{gathered}
$$

Here, the variable with overhat denotes the estimated value and $L$ is the observer gain. Different types of observers can be selected according to the system model and implication requirement.

\subsection{Estimation error analysis}

The estimation error of extended dynamic model $e_{\text {ext }}$ has to be constructed and analyzed in order to guarantee the stability and convergence of the observer system, and it can be defined as

$$
e_{\mathrm{ext}}=\left(x_{e}-\hat{x}_{e}\right)=\left\{\begin{array}{l}
e_{x} \\
e_{v}
\end{array}\right\}=\left\{\begin{array}{l}
x-\hat{x} \\
v-\hat{v}
\end{array}\right\} .
$$

Therefore, the dynamic model of the estimation error for the observer system can be obtained

$$
\begin{gathered}
\dot{e}_{\mathrm{ext}}=\left\{\begin{array}{l}
\dot{e}_{x} \\
\dot{e}_{v}
\end{array}\right\}=A_{b} e_{\mathrm{ext}}-L n, \\
A_{b}=\left(A_{e}-L C_{e}\right) .
\end{gathered}
$$

The dynamic behavior of the error model is affected by the system properties of the extended system and the observer gains, and the properties of the plant are unchangeable. So, in order to make the estimation error of dynamic model convergent to zero as fast as possible, it is important to select an appropriate observer gains.

\subsection{Observer gain design}

\subsubsection{Conventional PI observer method}

The conventional PI observer is an ideal observer model without considering the influence of measurement noise, which means that $n$ is zero, and its observer gain can be defined as [20]

$$
L=\left\{\begin{array}{l}
L_{x} \\
L_{v}
\end{array}\right\}=P^{-1} C_{e}^{T} .
$$

The Lyapunov function can choose a general quadratic function, which can be described as [26]

$$
V\left(e_{\text {ext }}\right)=\left(e_{\text {ext }}\right)^{T} P\left(e_{\text {ext }}\right) \text {. }
$$

Since the matrix $P$ is a symmetric positive definite matrix, $V\left(e_{\text {ext }}\right)$ is a positive definite function. The derivate against time of this function is given as

$$
\dot{V}\left(e_{\mathrm{ext}}\right)=\left(e_{\mathrm{ext}}\right)^{T}\left(\left(A_{e}-L C_{e}\right)^{T} P+P\left(A_{e}-L C_{e}\right)\right)\left(e_{\mathrm{ext}}\right) .
$$

If extend observer system is stable, the derivation of the Lyapunov function is negative definite. So, assuming the $\dot{V}\left(e_{\text {ext }}\right)=-\left(e_{\text {ext }}\right)^{T} Q\left(e_{\text {ext }}\right)$, equation (18) can be transformed into

$$
\left(A_{e}-L C_{e}\right)^{T} P+P\left(A_{e}-L C_{e}\right)+Q=0 .
$$

Here, $Q$ can be any arbitrary symmetric positive definite matrix. Substituting equations (15) and (16) into equation (19), an algebraic equation can be obtained as [26]

$$
P A_{e}+A_{e}^{T} P-2 C_{e}^{T} C_{e}+Q=0 .
$$

By multiplying a matrix $P^{-1}$ on both the left and right sides of equation (20), a new algebraic equation is derived as

$$
A_{e} P^{-1}+P^{-1} A_{e}^{T}-2 P^{-1} C_{e}^{T} C_{e} P^{-1}+P^{-1} Q P^{-1}=0 .
$$

We assume that $Q=b P^{2}$, in which $b$ denotes a scalar number for regulation of the final Riccati equation. In order to solve $P$, equation (21) can be transformed into a standard Riccati equation by defining $A_{k}=A_{e}{ }^{T}, P_{k}=P^{-1}$, $B_{k}=C_{e}^{T}$ and $R^{-1}=2 I$ as

$$
A_{k}^{T} P_{k}+P_{k} A_{k}-P_{k} B_{k} R^{-1} B_{k}^{T} P_{k}+b I=0 .
$$

Solving the standard Riccati equation, we can get a unique solution $P_{k}$. According to the relationship of $P_{k}$ and $P$, the observer gains then can be calculated by equation (16).

\subsubsection{Kalman filter method}

The Kalman filter is commonly used to estimate the system state variables with reduction of the influences caused by measurement noises. If the sensor output contains measurement noise, the method based on Kalman filter is used to deal with the measurement noise for the extended system. The discrete-time form of equations (7) and (8) is given as [26]

$$
\begin{aligned}
& x_{e}\left(t_{k+1}\right)=F\left(t_{k+1}, t_{k}\right) x_{e}\left(t_{k}\right), \\
& y\left(t_{k}\right)=C_{e}\left(t_{k}\right) x_{e}\left(t_{k}\right)+n\left(t_{k}\right) .
\end{aligned}
$$

Here, $F\left(t_{k+1}, t_{k}\right)$ denotes the transition matrix from the time $t_{k}$ to $t_{k+1}$. The connection between the continuoustime system and discrete-time system is taking a small time increment $\Delta=t_{k+1}-t_{k}$ :

$$
\begin{aligned}
\dot{x_{e}}\left(t_{k}\right) & =\frac{1}{\Delta}\left(x_{e}\left(t_{k+1}\right)-x_{e}\left(t_{k}\right)\right) \\
& =\frac{1}{\Delta}\left(\left(F\left(t_{k+1}, t_{k}\right)-I\right) x_{e}\left(t_{k}\right)\right) .
\end{aligned}
$$

When $\Delta$ tends to zero, the transition matrix has the following property:

$$
\frac{1}{\Delta}\left(F\left(t_{k+1}, t_{k}\right)-I\right)=A_{e}(t) .
$$


Kalman filter process for this system is given by [27]

$$
\begin{aligned}
P\left(t_{k+1} \mid t_{k}\right)=F\left(t_{k+1}, t_{k}\right) P\left(t_{k} \mid t_{k}\right) F\left(t_{k+1}, t_{k}\right)^{T} & \\
w\left(t_{k+1}\right)= & P\left(t_{k+1} \mid t_{k}\right) C_{e}\left(t_{k+1}\right)^{T} \\
& \times\left(C_{e}\left(t_{k+1}\right) P\left(t_{k+1} \mid t_{k}\right) C_{e}\left(t_{k+1}\right)^{T}+R\left(t_{k+1}\right)\right)^{-1}
\end{aligned}
$$$$
\hat{x}_{e}\left(t_{k+1} \mid t_{k}\right)=F\left(t_{k+1}, t_{k}\right) \hat{x}_{e}\left(t_{k} \mid t_{k}\right)
$$$$
\hat{x}_{e}\left(t_{k+1} \mid t_{k+1}\right)=\hat{x}_{e}\left(t_{k+1} \mid t_{k}\right)+w\left(t_{k+1}\right)\left(y\left(t_{k+1}\right)\right.
$$$$
\left.-C_{e}\left(t_{k+1}\right) \hat{x}_{e}\left(t_{k+1} \mid t_{k}\right)\right) \text {, }
$$

$$
P\left(t_{k+1} \mid t_{k+1}\right)=\left(I-w\left(t_{k+1}\right) C_{e}\left(t_{k+1}\right)\right) P\left(t_{k+1} \mid t_{k}\right) .
$$

After division by $\Delta$, equation (30) can be described as

$$
\begin{gathered}
\frac{1}{\Delta}\left(\hat{x}_{e}\left(t_{k+1} \mid t_{k+1}\right)-\hat{x}_{e}\left(t_{k} \mid t_{k}\right)\right)=\frac{1}{\Delta}\left(F\left(t_{k+1}, t_{k}\right)-I\right) \hat{x}_{e}\left(t_{k} \mid t_{k}\right) \\
+w\left(t_{k+1}\right)\left(y\left(t_{k+1}\right)-\hat{y}\left(t_{k+1}\right)\right) .
\end{gathered}
$$

Using equation (28), equation (32) can be translated into the following form [28]:

$$
\begin{aligned}
\frac{1}{\Delta}\left(\hat{x}_{e}\left(t_{k+1} \mid t_{k+1}\right)-\hat{x}_{e}\left(t_{k} \mid t_{k}\right)\right) \\
=\frac{1}{\Delta}\left(\left(F\left(t_{k+1}, t_{k}\right)-I\right) \hat{x}_{e}\left(t_{k} \mid t_{k}\right)\right)+P\left(t_{k+1} \mid t_{k}\right) C_{e}\left(t_{k+1}\right)^{T} \\
\quad \times\left(C_{e}\left(t_{k+1}\right) P\left(t_{k+1} \mid t_{k}\right) C_{e}\left(t_{k+1}\right)^{T} \Delta+R\left(t_{k+1}\right) \Delta\right)^{-1} \\
\quad \times\left(y\left(t_{k+1}\right)-\hat{y}\left(t_{k+1}\right)\right) .
\end{aligned}
$$

When the time interval $\Delta$ approaches zero, it leads to $R\left(t_{k+1}\right) \Delta=R_{N}\left(t_{k+1}\right)$. One obtains the following equation after dropping the subscript of $t$ :

$$
\dot{\hat{x}}_{e}=A_{e} \hat{x}_{e}+L(y-\hat{y}),
$$

where the optimal continuous-time filter gain is

$$
L=\left[\begin{array}{l}
L_{x} \\
L_{v}
\end{array}\right]=P C_{e}^{T} R_{N}^{-1} .
$$

The discrete-time covariance update equation can be written as

$$
\begin{aligned}
P\left(t_{k+1} \mid t_{k+1}\right)= & \left(I-w\left(t_{k+1}\right) C_{e}\left(t_{k+1}\right)\right) \\
& \times F\left(t_{k+1}, t_{k}\right) P\left(t_{k} \mid t_{k}\right) F\left(t_{k+1}, t_{k}\right)^{T} .
\end{aligned}
$$

Substituting equation (28) into equation (36), the new form of the discrete-time covariance update equation can be obtained [28]:

$$
\begin{aligned}
P\left(t_{k+1} \mid t_{k+1}\right)= & P\left(t_{k} \mid t_{k}\right)+A_{e}\left(t_{k}\right) P\left(t_{k} \mid t_{k}\right) \Delta \\
& +P\left(t_{k} \mid t_{k}\right) A_{e}\left(t_{k}\right)^{T} \Delta-P\left(t_{k+1} \mid t_{k}\right) C_{e}\left(t_{k+1}\right)^{T} \\
& \times R\left(t_{k+1}\right)^{-1} C_{e}\left(t_{k+1}\right)^{T} P\left(t_{k+1} \mid t_{k}\right) .
\end{aligned}
$$

Here the term in $\Delta^{2}$ has been neglected. In difference form, one has

$$
\begin{aligned}
& \frac{1}{\Delta}\left(P\left(t_{k+1} \mid t_{k+1}\right)-P\left(t_{k} \mid t_{k}\right)\right) \\
& \quad=A_{e}\left(t_{k}\right) P\left(t_{k} \mid t_{k}\right)+P\left(t_{k} \mid t_{k}\right) A_{e}\left(t_{k}\right)^{T} \\
& \quad-P\left(t_{k+1} \mid t_{k}\right) C_{e}\left(t_{k+1}\right)^{T}\left(R\left(t_{k+1}\right) \Delta\right)^{-1} C_{e}\left(t_{k+1}\right)^{T} P\left(t_{k+1} \mid t_{k}\right) .
\end{aligned}
$$

Under the assumption of continuity, one gets $P\left(t_{k+1} \mid t_{k}\right) \triangleq P\left(t_{k} \mid t_{k}\right)$ if the time $\Delta$ tends to zero. Assuming $\dot{P}=-Q$, the algebraic Riccati equation for the state estimate covariance of the extend system can be obtained.

$$
A_{e} P+P A_{e}^{T}-P C_{e}^{T} R_{N}{ }^{-1} C_{e} P+Q=0 .
$$

Assuming $A_{k}=A_{e}{ }^{T}, \quad B_{k}=C_{e}{ }^{T}$, equation (39) can be transformed into the standard algebraic Riccati equation:

$$
A_{k}^{T} P+P A_{k}-P B_{k} R_{N}^{-1} B_{k}^{T} P+Q=0 .
$$

We can get the value of matrix $P$ by solving equation (40). On this basis, the gain of the observer can be obtained according to equation (35). In addition, estimator gain $L$ can also be obtained by calling Kalman function in MATLAB.

\subsection{Disturbance estimation system}

Defining $\hat{x}_{e}$ as the state vector of disturbance estimation system, sensor output signal $y$ as the system input signal, estimated disturbance $\hat{f}$ as the system output signal, a closed-loop state space model integrated with disturbance observer can be constructed according to equations (11) and (12) as

$$
\dot{\hat{x}}_{e}=\left[\begin{array}{cc}
A-L_{x} C & N H \\
-L_{v} C & V
\end{array}\right] \hat{x}_{e}+\left[\begin{array}{c}
L_{x} \\
L_{v}
\end{array}\right] y,
$$

$$
\hat{f}=\left[\begin{array}{ll}
0 & H
\end{array}\right] \hat{x}_{e} .
$$

From equations (41) and (42), it can be known that if the sensor output $y$ is obtained, the unknown disturbance force can be estimated. 


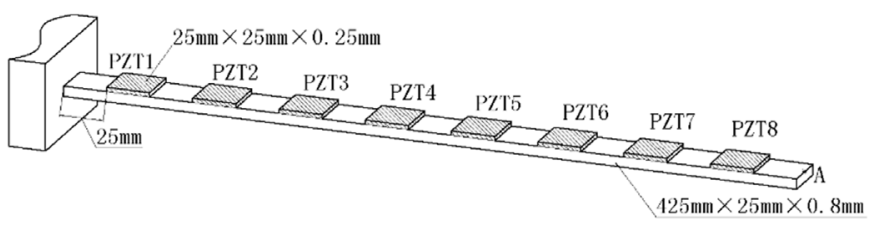

Fig. 1. The dimension and structure layout of a cantilever beam.
Table 1. Material properties of the cantilever beam.

\begin{tabular}{lll}
\hline Material name & Spring steel & PZT \\
\hline Elastic modulus $Y$ & $210 \mathrm{GPa}$ & $66.667 \mathrm{GPa}$ \\
Poisson's ratio $v$ & 0.3 & 0.34 \\
Density $\rho$ & $7900 \mathrm{~kg} / \mathrm{m}^{3}$ & $7800 \mathrm{~kg} / \mathrm{m}^{3}$ \\
Piezoelectric constant & & $-2.1 \times 10^{-10} \mathrm{C} / \mathrm{N}$ \\
$d_{31}=d_{32}$ & & $2.125 \times 10^{-8} \mathrm{~F} / \mathrm{m}$ \\
Dielectric constant $\varepsilon_{33}$ & & \\
\hline
\end{tabular}

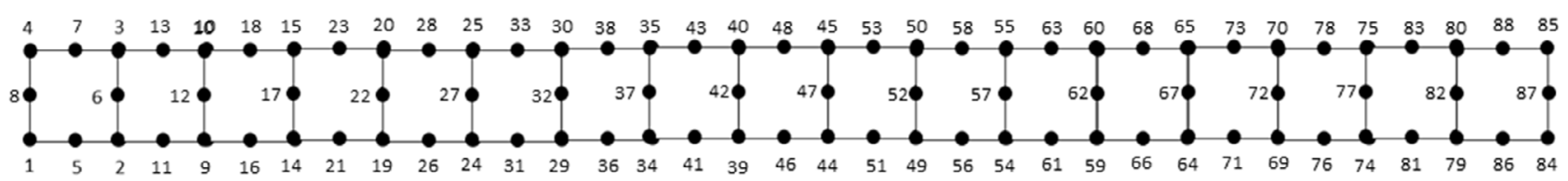

Fig. 2. Mesh and node index of the cantilever beam.

\section{Dynamic model of a piezoelectric integrated smart structure}

By applying the FE method and Hamilton's principle, the electromechanically coupled dynamic FE model of piezoelectric smart structure can be obtained, which is known as the equation of motion and the sensor equation, respectively, as $[29,30]$

$$
\begin{gathered}
M_{\mathrm{uu}} \ddot{q}+C_{\mathrm{uu}} \dot{q}+K_{\mathrm{uu}} q+K_{\mathrm{u} \varnothing} \varnothing_{a}=F_{\mathrm{ue}}, \\
K_{\varnothing \mathrm{u}} q+K_{\varnothing \varnothing} \varnothing_{s}=0
\end{gathered}
$$

where $M_{\mathrm{uu}}, C_{\mathrm{uu}}, K_{\mathrm{uu}}, K_{u \varnothing}, K_{\varnothing \mathrm{u}}$ and $K_{\varnothing \varnothing}$ indicate the mass, the damping, the stiffness, the piezoelectric coupled stiffness, the coupled capacity and the piezoelectric capacity matrices, respectively. Furthermore, $q, F_{\text {ue }}, \varnothing_{\text {a }}$, $\varnothing_{\mathrm{s}}$ are the nodal displacement vector, the external force vector, the actuator driving voltage vector and the sensor output voltage vector, respectively.

A general FE model usually has hundreds of nodal degrees of freedom. In order to decrease the computation time, a truncated modal matrix $S_{\mathrm{r}}$ is used to reduce the number of equations in the state space, as well as the modes that are considered. Using the truncated modal matrix, higher order modes are neglected, and only the main first several modes are considered. The decomposed and reduced motion equation and sensor equation can be achieved as [21]

$$
\begin{gathered}
M_{\mathrm{uu}}^{\mathrm{m}} \ddot{z}_{r}+C_{\mathrm{uu}}^{\mathrm{m}} \dot{z}_{r}+K_{\mathrm{uu}}^{\mathrm{m}} z_{r}=S_{\mathrm{r}}^{\mathrm{T}} F_{\mathrm{ue}}-S_{\mathrm{r}}^{\mathrm{T}} K_{\mathrm{u} \emptyset} \emptyset_{\mathrm{a}}, \\
\varnothing_{\mathrm{s}}=-K_{\varnothing \varnothing}^{-1} K_{\emptyset \mathrm{u}} S_{\mathrm{r}} z_{\mathrm{r}} .
\end{gathered}
$$

Here, $M_{\mathrm{uu}}^{\mathrm{m}}, C_{\mathrm{uu}}^{\mathrm{m}}, K_{\mathrm{uu}}^{\mathrm{m}}$ are the modal mass, damping and stiffness matrices, respectively. In addition, $z_{\mathrm{r}}$ denotes the reduced modal coordinates.
Defining $x=\left\{\begin{array}{l}z_{\mathrm{r}} \\ \dot{z}_{\mathrm{r}}\end{array}\right\}$ as the state variable, $\varnothing_{\mathrm{s}}$ as the output signal and $F_{\text {ue }}$ as the external unknown disturbance. In addition, assuming the actuator driving voltage vector $\varnothing_{\mathrm{a}}$ is zero. According to the state space model, given in equations (2) and (3), matrix $A, N, C$ can be given as

$$
\begin{gathered}
A=\left[\begin{array}{cc}
0 & I \\
-\left(M_{\mathrm{uu}}^{\mathrm{m}}\right)^{-1} K_{\mathrm{uu}}^{\mathrm{m}} & -\left(M_{\mathrm{uu}}^{\mathrm{m}}\right)^{-1} C_{\mathrm{uu}}^{\mathrm{m}}
\end{array}\right], \\
N=\left[\begin{array}{c}
0 \\
-\left(M_{\mathrm{uu}}^{\mathrm{m}}\right)^{-1} S_{\mathrm{r}}^{\mathrm{T}}
\end{array}\right], \\
C=\left[\begin{array}{ll}
-K_{\varnothing \varnothing}^{-1} K_{\varnothing \mathrm{u}} S_{\mathrm{r}} & 0
\end{array}\right] .
\end{gathered}
$$

\section{Disturbance estimation simulation}

\subsection{Numerical example and validation test}

A cantilever beam integrated with eight piezoelectric (PZT) patches is used for the simulation test, as is shown in Figure 1. The dimensions of the host structure are $425 \mathrm{~mm} \times 25 \mathrm{~mm} \times 0.8 \mathrm{~mm}$, and the size of the piezoelectric patches is $25 \mathrm{~mm} \times 25 \mathrm{~mm} \times 0.25 \mathrm{~mm}$. The spaces between two neighboring piezoelectric patches are all same and equal to $25 \mathrm{~mm}$. The polarization of piezoelectric patches is along the direction pointing outward normal to the host structure surface. The electric potentials of the inner surfaces of the piezoelectric patches which bonded to the surface of the host structure are connected to the ground. The piezoelectric patches are acted as sensors generating voltages when strain changes. For finite element model, the structure is meshed by 17 eight-node quadrilateral elements, as presented in Figure 2.

The host structure of the cantilever beam is made of spring steel, whose material properties are shown in Table 1. 
Table 2. Voltages applied on eight PZT patches (volts).

\begin{tabular}{lllllllll}
\hline & PZT1 & PZT2 & PZT3 & PZT4 & PZT5 & PZT6 & PZT7 & PZT8 \\
\hline Case 1 & -110.31 & -61.18 & -90.83 & -82.25 & -84.93 & -84.06 & -85.28 & -79.42 \\
Case 2 & 127.67 & 188.91 & 75.91 & -112.40 & -195.79 & -100.08 & 90.73 & 182.37 \\
\hline
\end{tabular}

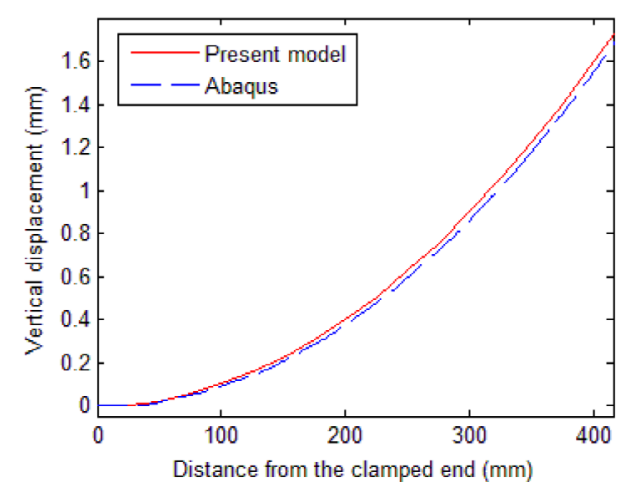

(a) Case 1

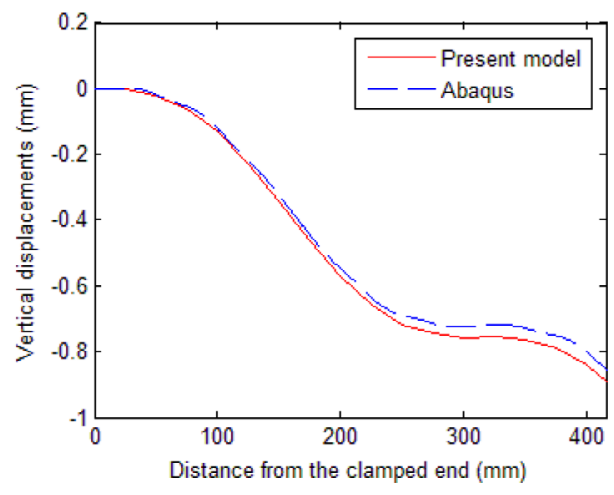

(b) Case 2

Fig. 3. Central line displacements of the clamped beam.

Table 3. The first 12 eigenfrequency of PZT cantilever beam.

\begin{tabular}{llllllllllllll}
\hline Method & \multicolumn{10}{c}{ Eigenfrequencies } \\
\cline { 2 - 13 } & 1 & 2 & 3 & 4 & 5 & 6 & 7 & 8 & 9 & 10 & 11 & 12 \\
\hline Present model & 3.79 & 23.80 & 67.08 & 110.34 & 127.90 & 133.02 & 223.63 & 341.36 & 384.43 & 488.83 & 643.13 & 681.95 \\
Abaqus & 3.80 & 23.80 & 66.82 & 107.58 & 121.62 & 131.14 & 217.16 & 325.04 & 358.73 & 454.97 & 590.87 & 606.58 \\
\hline
\end{tabular}

To validate the finite element model of the clamped beam bonded with multiple piezoelectric patches, static and dynamic behavior is studied and compared with those calculated by Abaqus. For static analysis, two sets of voltages are applied respectively to eight patches of PZT, given in Table 2. The displacements of the central line of the clamped beam calculated by the present finite element model and Abaqus are almost identical for both cases, as shown in Figure 3. For dynamic analysis, the first 12 eigenfrequencies of the cantilever beam calculated by the present finite element model and Abaqus are given in Table 3 . Table 3 shows that the eigenfrequencies calculated by the present model are very close to those by Abaqus, especially for the first six eigenfrequencies.

\subsection{Disturbance estimation with measurement noise}

In order to decrease the computation time, the dynamic FE model is reduced to retain the first 12 modes. In the presence of the measurement noise, different types of disturbances are applied at point $\mathrm{A}$ of the cantilever beam. When PI observer is used to estimate the external unknown disturbance, the observer gains are obtained by solving algebraic Riccati equation in equation (22) using $b=10,000$. In addition, the variance $R_{\mathrm{N}}$ of the measurement noise is set to be identity matrix, which is presented in equation (39).

In order to quantitatively evaluate the impact of measurement noise on the estimation performance, the relative error of estimation process for the external unknown disturbance is introduced in the analysis of simulation results, and it can be defined as [31]

$$
\varepsilon=\frac{\frac{1}{\sqrt{n}}\|\hat{f}-f\|_{2}}{\|f\|_{2}}=\frac{\frac{1}{\sqrt{n}} \sqrt{\sum_{i=1}^{n}\left(\hat{f}_{i}-f_{i}\right)^{2}}}{\sqrt{\sum_{i=1}^{n}\left(f_{i}\right)^{2}}}
$$

where $n$ is the number of sampling points, $\hat{f}$ and $f$ are the value of the estimated disturbance and the actual disturbance.

In order to describe the results more clearly, several abbreviations are introduced in this paper. Conventional PI observer method proposed by Müller and PI observer based on Kalman filter are abbreviated, respectively, as PI-Müller and PI-Kalman. Furthermore, measurement noise is represented by MN. 


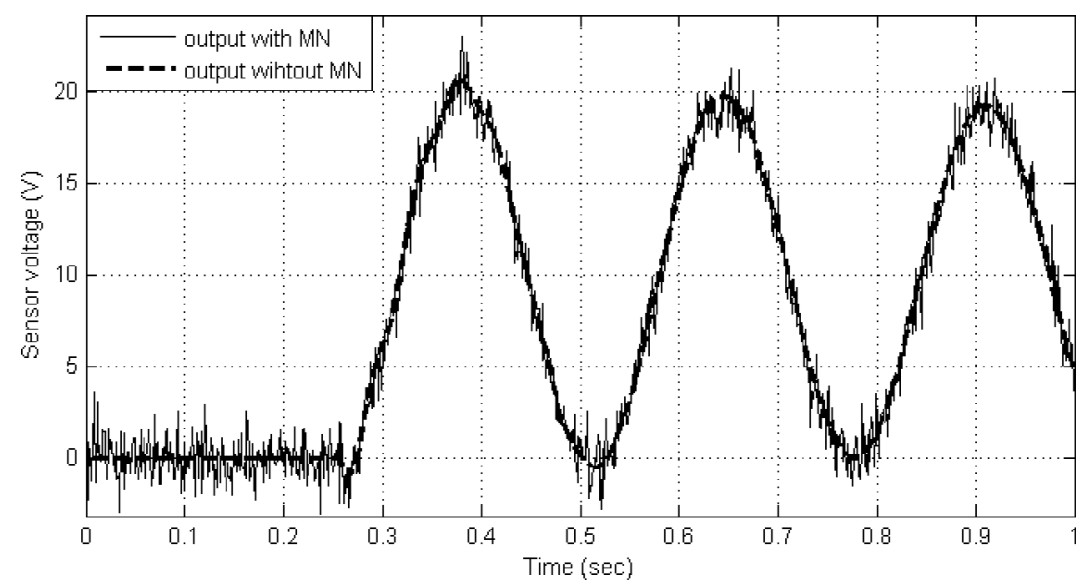

(a) Piezoelectric sensor 1 output signals

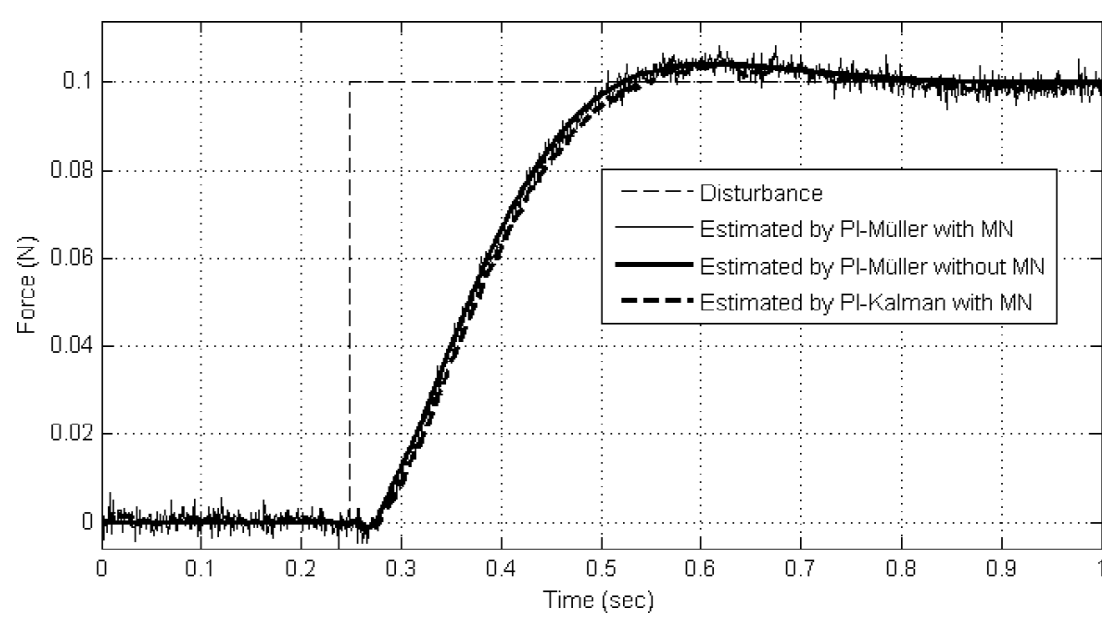

(b) Estimated disturbances

Fig. 4. Estimated step disturbances with piezoelectric sensors 1.

Table 4. The relative error of the estimated disturbance with MN using PZT1.

\begin{tabular}{llll}
\hline Disturbance & \multicolumn{3}{c}{ The relative error $\varepsilon$} \\
\cline { 2 - 4 } & PI-Müller without MN & PI-Müller with MN & PI-Kalman with MN \\
\hline Step disturbance time 0-1 s & $1.08 \times 10^{-2}$ & $1.10 \times 10^{-2}$ & $1.09 \times 10^{-2}$ \\
Cosine disturbance time 0-2 s & $1.77 \times 10^{-2}$ & $1.81 \times 10^{-2}$ & $1.79 \times 10^{-2}$ \\
\hline
\end{tabular}

\subsubsection{Step disturbance}

The cantilever beam is assumed to be excited by an unknown step disturbance, which occurs at $0.25 \mathrm{~s}$ with the amplitude of $0.1 \mathrm{~N}$. The output signal of piezoelectric sensor 1 is presented in Figure 4a, which shows that the sensor output with $\mathrm{MN}$ or without MN have the similar mean value, but the former one has significant fluctuations. The estimated disturbances obtained by PI-Müller or PI-Kalman are shown in Figure 4b. The results show that the estimated disturbances obtained by PI-Müller or
PI-Kalman have the similar mean value. The latter one considers the measurement noise in computation of observer gains. Therefore, the estimated disturbance is smoother than the one estimated by PI-Müller. Moreover, the results of PI-Kalman with MN is very close to that of PI- Müller without MN.

The relative error of an estimated disturbance $\varepsilon$ is presented in Table 4. From the table, it can be seen that the relative error of the estimated disturbance by PI-Müller or PI-Kalman are close to each other regardless of the sensor output with or without noise. 


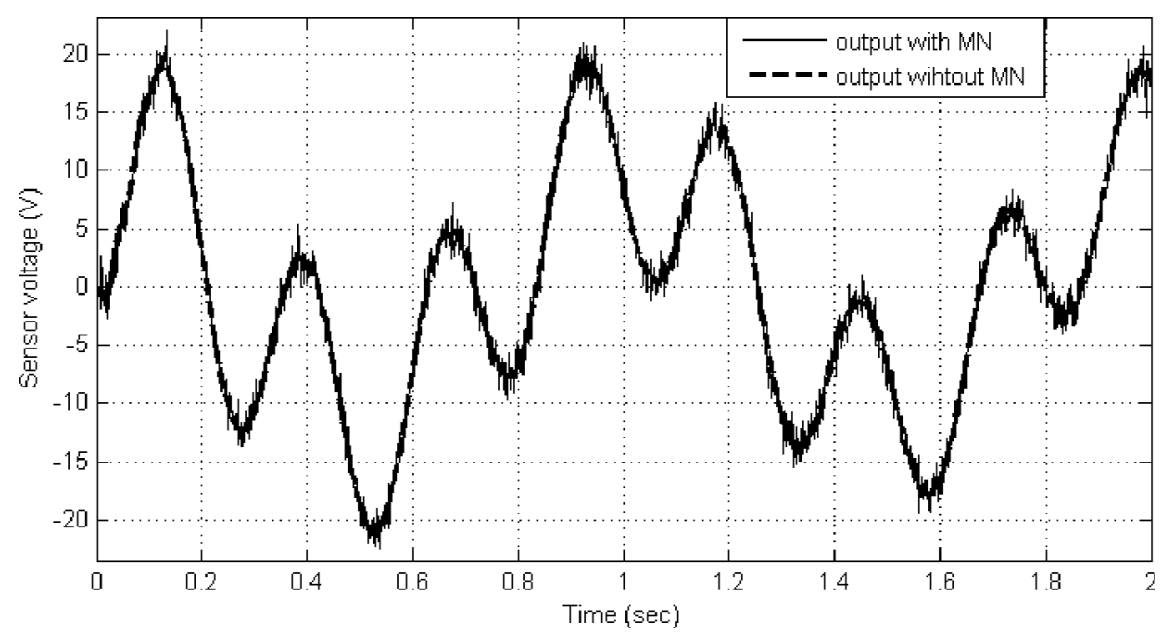

(a) Piezoelectric sensor 1 output signals

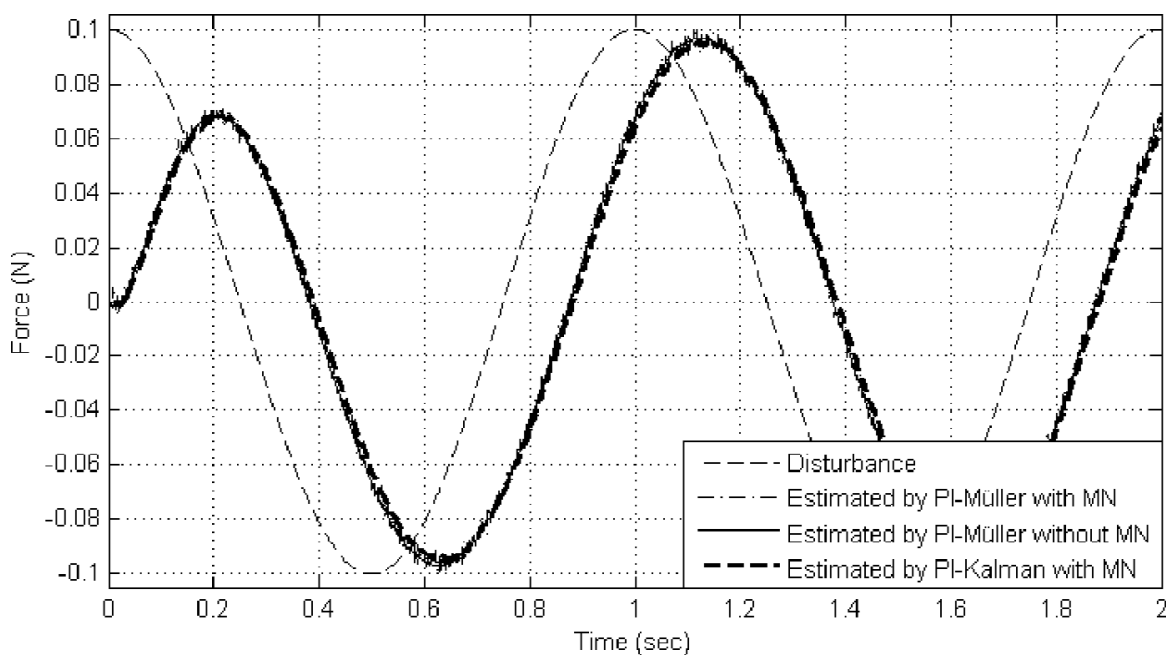

(b) Estimated disturbances

Fig. 5. Estimated cosine disturbances with piezoelectric sensors 1.

\subsubsection{Harmonic disturbance}

A cosine disturbance force described by the function $f(t)=0.1 \cos 2 \pi t N$ is applied at point $A$ of the cantilever beam. The output dynamic response of piezoelectric sensor 1 and the estimated disturbances are shown in Figures $5 \mathrm{a}$ and $5 \mathrm{~b}$, respectively. As is from Figure $5 \mathrm{a}$, although sensor output with MN has more burrs than sensor output without MN, their mean value are almost identical. From Figure 5b, a similar conclusion can be drawn as that from the previous one. However, for the periodic disturbance, phase shifting may exist. This is due to the fact that for any estimation the PI observer needs rising time, especially for those varying fast. The relative error of estimated disturbance is presented in Table 4, from which the PI-Kalman with MN results shows a smaller deviation than those obtained by PI-Müller with MN, compared to those of PI-Müller without MN.

\subsection{Using various numbers of piezoelectric sensors}

From the previous section, we know that PI-Kalman with MN and PI-Müller without MN have very similar function, both of them can estimate unknown disturbances. In order to show clearly the following simulations, the case of PI-Müller without MN will be considered.

\subsubsection{Step disturbance}

In this section, the influence of unknown disturbances using various numbers of piezoelectric sensors is investigated. The cantilever beam is assumed to be excited by an unknown step disturbance, which occurs at $0.25 \mathrm{~s}$ with the amplitude of $0.1 \mathrm{~N}$. The voltage output of the eight piezoelectric sensors are presented in Figure 6a, which show that the amplitudes of piezoelectric sensors output decrease from PZT1 to PZT8. This can be explained by the fact that the strains always occur 


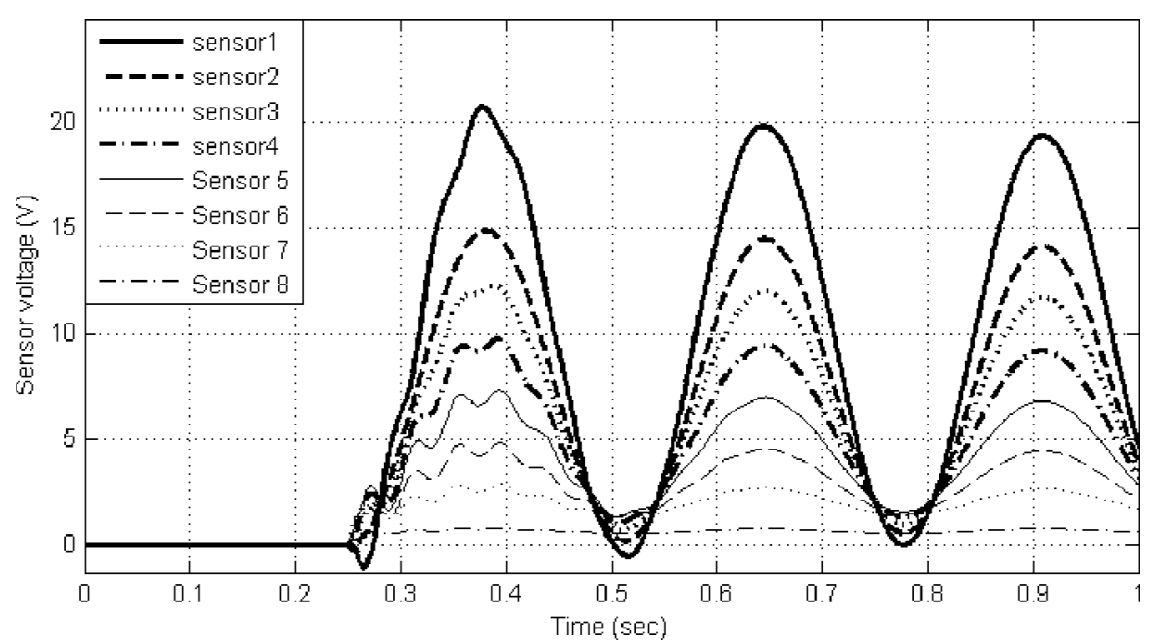

(a) Piezoelectric sensor output signals

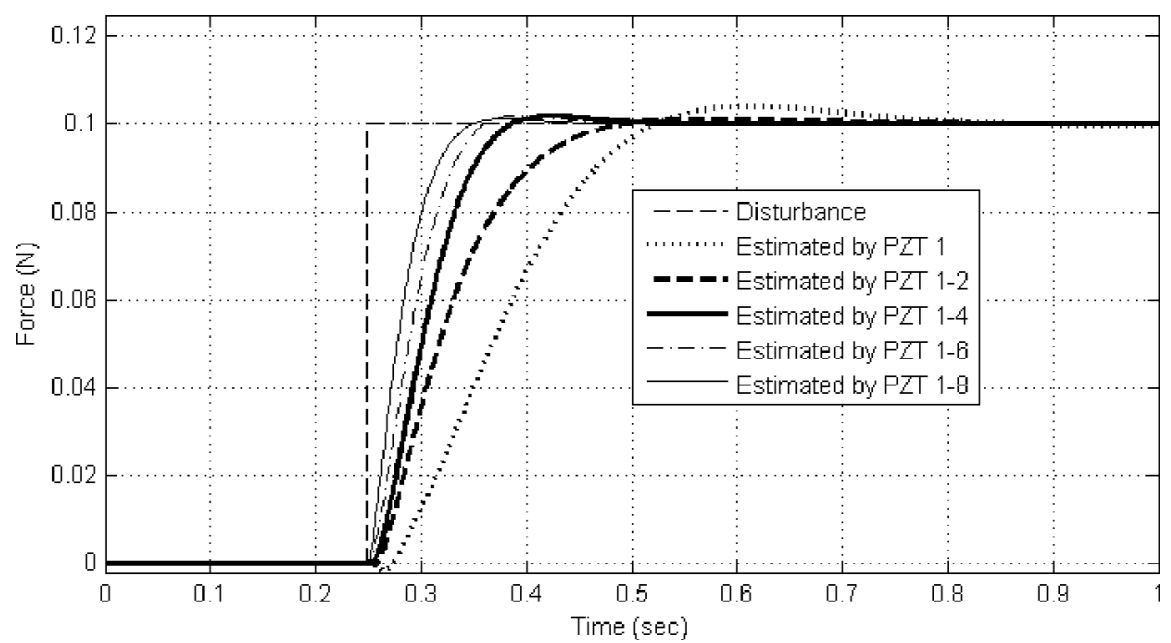

(b) Estimated disturbances

Fig. 6. Estimated step disturbances for the cantilevered beam using various numbers of piezoelectric sensors.

Table 5. The relative error of estimated disturbance with different numbers of piezoelectric sensors.

\begin{tabular}{llll}
\hline Sensor & \multicolumn{2}{c}{ The relative error $\varepsilon$} \\
\cline { 2 - 4 } & $\begin{array}{l}\text { Step disturbance } \\
\text { time 0-1 s }\end{array}$ & $\begin{array}{l}\text { Cosine disturbance } \\
\text { time 0-1.5 s }\end{array}$ & $\begin{array}{l}\text { Triangle wave disturbance } \\
\text { time 0-1.5 s }\end{array}$ \\
\hline PZT 1 & $1.10 \times 10^{-2}$ & $2.08 \times 10^{-2}$ & $2.09 \times 10^{-2}$ \\
PZT 1-2 & $0.83 \times 10^{-2}$ & $1.41 \times 10^{-2}$ & $1.42 \times 10^{-2}$ \\
PZT 1-4 & $0.72 \times 10^{-2}$ & $1.10 \times 10^{-2}$ & $1.13 \times 10^{-2}$ \\
PZT 1-6 & $0.62 \times 10^{-2}$ & $0.84 \times 10^{-2}$ & $0.90 \times 10^{-2}$ \\
PZT 1-8 & $0.53 \times 10^{-2}$ & $0.67 \times 10^{-2}$ & $0.73 \times 10^{-2}$ \\
\hline
\end{tabular}

largest at the clamped end and reduce with approaching to the free end. Employing different numbers of piezoelectric patches obtains the estimated disturbances, which is shown in Figure 6b. The results show that the rising time of the estimated disturbance shortens dramatically and the overshoot decreases by increasing the number of measurements.
Furthermore, the relative error of estimate, presented in Table 5, become smaller and smaller by increasing the number of measurement points, and the change trend is illustrated in Figure 7. Therefore, the estimated disturbance using eight piezoelectric patches has the minimum estimation error and yields the best estimation effect compared to other configurations. 


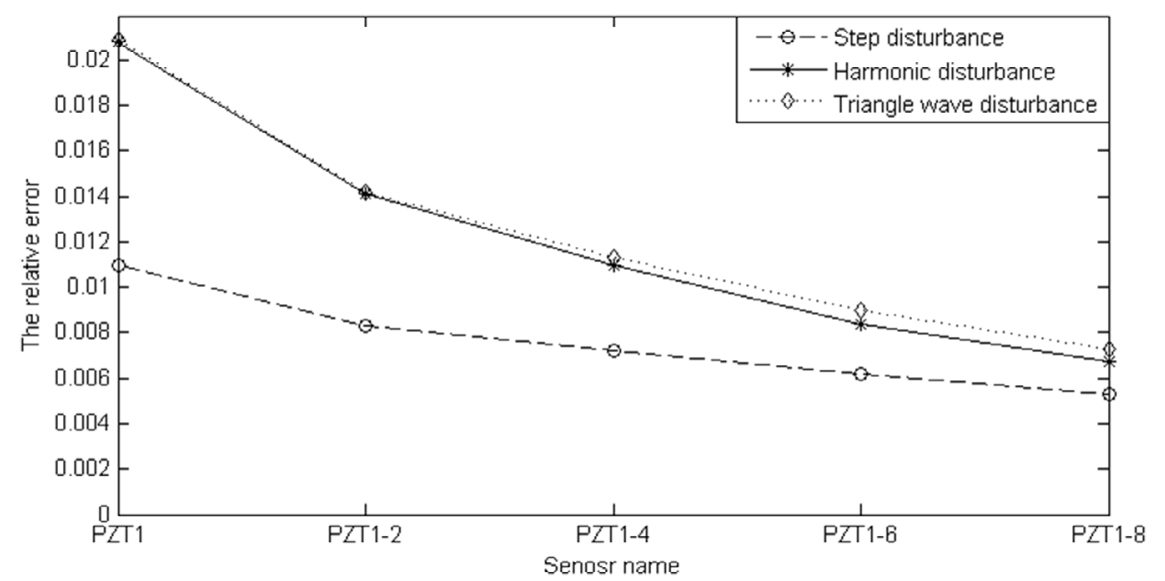

Fig. 7. The relative error of estimated disturbances for the cantilevered beam with various numbers of piezoelectric sensors.

\subsubsection{Harmonic disturbance}

In the second simulation, a cosine disturbance force described by the function $f(t)=0.1 \cos 2 \pi t N$ is applied at point $A$ of the cantilever beam. The output dynamic response of piezoelectric sensors is shown in Figure 8a. Similarly, the amplitudes of sensor signals decrease from PZT1 to PZT8. The estimated step disturbances using various numbers of piezoelectric patches are presented in Figure $8 \mathrm{~b}$. Figure $8 \mathrm{~b}$ shows that the rising time always exists, but it will be significantly shortened by increasing the number of sensor measurements. In addition, as is known from Table 5 and Figure 7 that the relative error of estimated disturbance become smaller by increasing the number of PZT sensors and the estimated disturbance by eight piezoelectric patches has the minimum error. It implies that the dynamic performance of estimation system can be improved by increasing the number of measurement points.

\subsubsection{Triangle wave disturbance}

The angular frequency $\omega$ of triangle wave disturbance is $2 \pi \mathrm{rad} / \mathrm{s}$ with the amplitude of $0.1 \mathrm{~N}$. The signals of piezoelectric sensors and the estimated disturbances are shown in Figures 9a and 9b, respectively. The phenomenon observed is similar to the previous simulation by using various numbers of PZT sensors. The response speed of estimated disturbance by eight piezoelectric sensors is the fastest and the relative error (presented in Tab. 5) is the minimum among all configurations. Moreover, the change trend of the relative error illustrated in Figure 7 is the same as the previous description. This fact shows that the estimated disturbance is closer to the original disturbance with the number increase of piezoelectric sensors.

\subsection{Using various positions of measurements}

\subsubsection{Step disturbance}

In order to analyze the influence of measurement points, different positions of PZT sensors are used to estimate the unknown disturbances. A step disturbance force occurs at point $A$ of the cantilever beam at $0.25 \mathrm{~s}$ with the amplitude of $0.1 \mathrm{~N}$. The voltage outputs of eight PZT sensors are same as Figure 6a, and the estimated disturbances are presented in Figure 10. From Figure 10, it is difficult to evaluate estimation performance of different position sensors because the estimated disturbances rise faster and the overshoot become greater from PZT1 to PZT8.

However, the disturbance estimated by PZT8 has the minimum relative error which is equal to $0.74 \times 10^{-2}$ according to Table 6 and Figure 11, and it implies that using PZT8 to estimate the disturbance lead to good dynamic performance compared with the use of other position PZT sensors.

\subsubsection{Harmonic disturbance}

The cantilever beam is excited by a cosine disturbance force following the function $f(t)=0.1 \cos 2 \pi t \mathrm{~N}$, and various positions of PZT sensors are used to estimate the unknown disturbance. The output signals of eight PZT sensors are same as Figure 8a, and estimated disturbances are displayed in Figure 12. When the PZT sensor position is gradually close to the free end of the cantilever beam, the response speed of estimated disturbance increases and the time delay becomes small. Furthermore, the relative error shown in Table 6 decreases from PZT1 to PZT8. This change trend illustrated in Figure 11 is obvious and the relative error of disturbance estimated by PZT8 is the smallest compared to other measurement points. This fact shows that the disturbance estimated by using PZT8 has better dynamic performance compared with other layouts.

\subsubsection{Triangle wave disturbance}

The triangle wave disturbance force with the amplitude of $0.1 \mathrm{~N}$ and the angular frequency of $2 \pi \mathrm{rad} / \mathrm{s}$ is simulated in this test. As described above, PZT sensor with various positions is used to estimate the unknown disturbance. Similarly, the output signals of eight PZT sensors are same as Figure 9a. The estimated disturbances, displayed in Figure 13, illustrate that the rise time decreases and time 


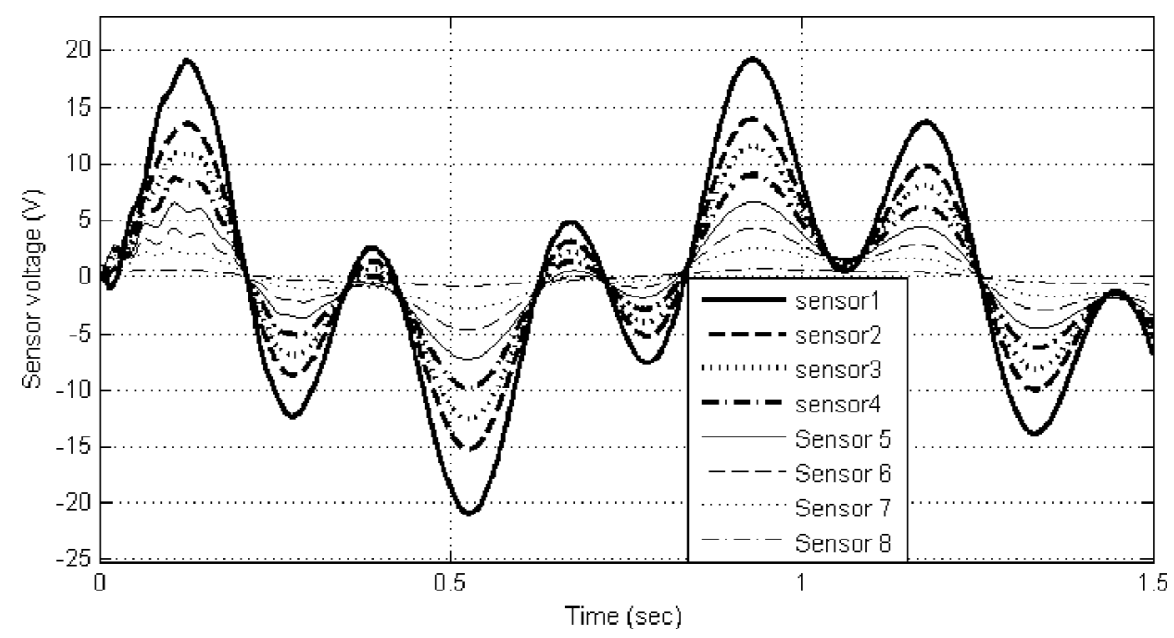

(a) Piezoelectric sensor output signals

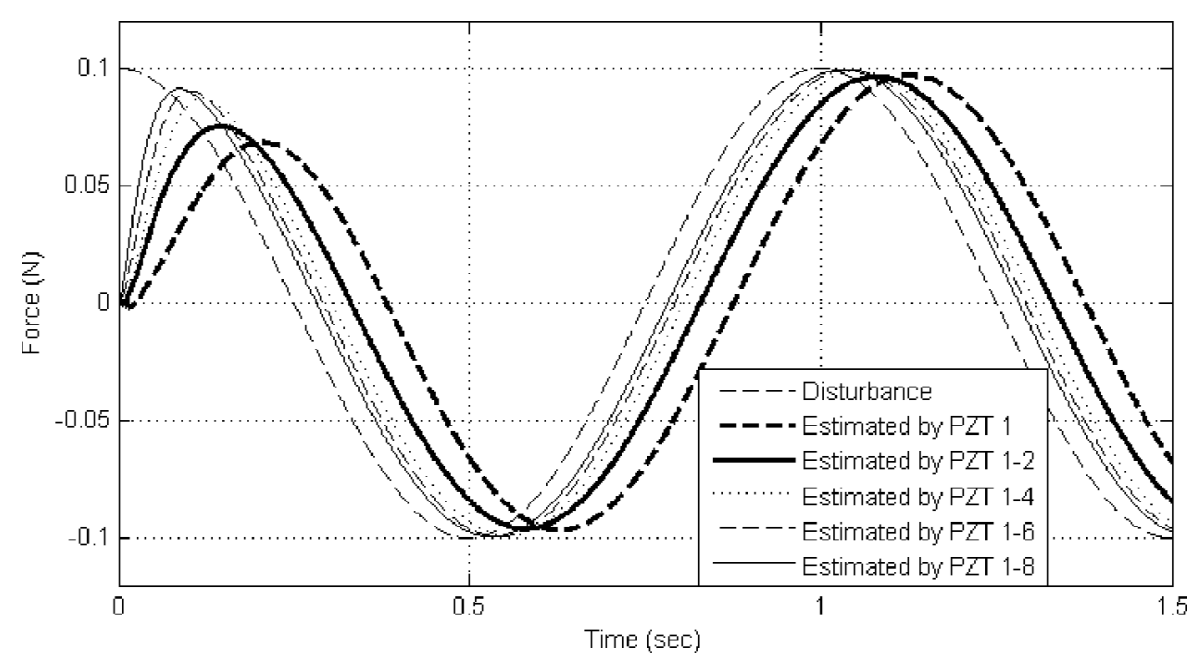

(b) Estimated disturbances

Fig. 8. Estimated harmonic disturbances for the cantilevered beam using various numbers of piezoelectric sensors.

delay becomes smaller when piezoelectric sensor is gradually near to the free end of the beam. According to the change trend shown in Figure 11, it is obvious that the relative error decreases from PZT1 to PZT8, and the disturbance estimated by PZT8 has the minimum relative error. The result illustrates that the PZT sensor near the free end of cantilevered beam has good estimation effect compared to other arrangements, similar to the cosine disturbance.

\subsubsection{Step disturbance estimation by two piezoelectric sensors}

Two PZT sensors with different positions are used to estimate the unknown disturbance in order to further investigate the influence of measurement layout. A step disturbance force with the amplitude of $0.1 \mathrm{~N}$ acts on point $A$ of the cantilever beam at $0.25 \mathrm{~s}$. The output signals of the eight PZT sensors have no change and are same as Figure 6a. The estimated disturbances are shown in the
Figure 14 by using two PZT sensors with different positions. It is obvious that the estimated disturbance by PZT1 and PZT8 has the minimum rise time and overshoot. The result implies that the combination of PZT1 and PZT8 have better estimation effect compared to other arrangements.

\section{Conclusion}

A disturbance estimation method has been developed for a general structural systems based on finite element model and state observer theory. The effect of measurement noise on estimation performance under different disturbance is analyzed when PI-Müller or PI-Kalman is used. The proposed disturbance estimation method is implemented into a piezoelectric smart structure under various type unknown disturbances. Simulation results show that the accuracy of disturbance estimation is greatly affected by the number and location of the 


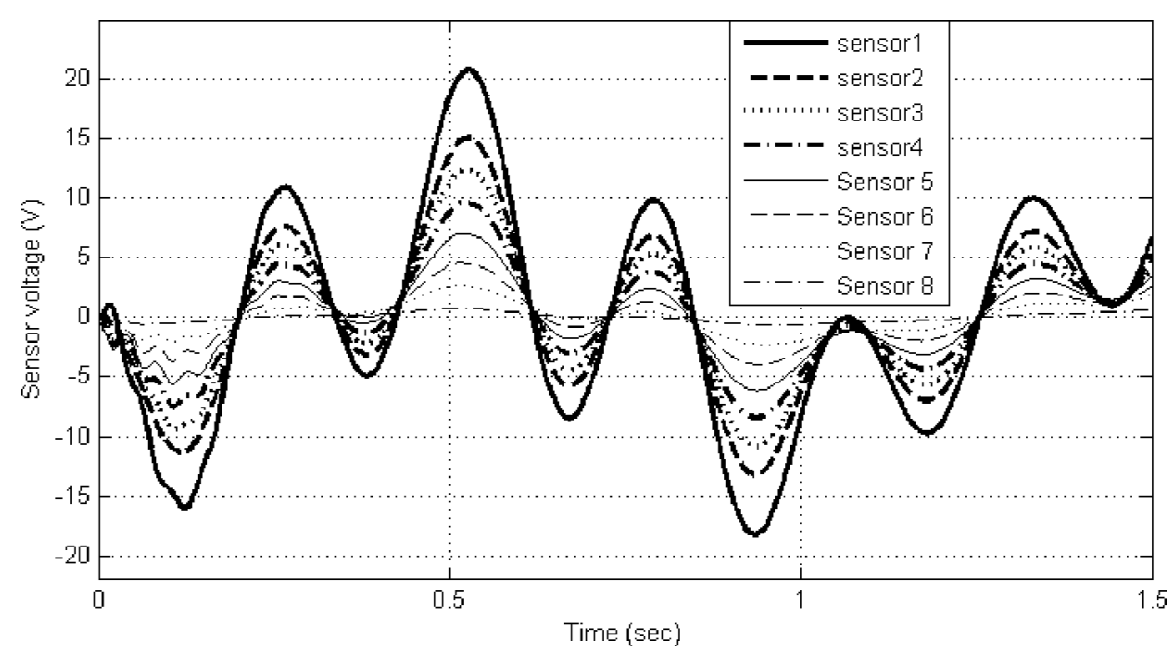

(a) Piezoelectric sensor output signals

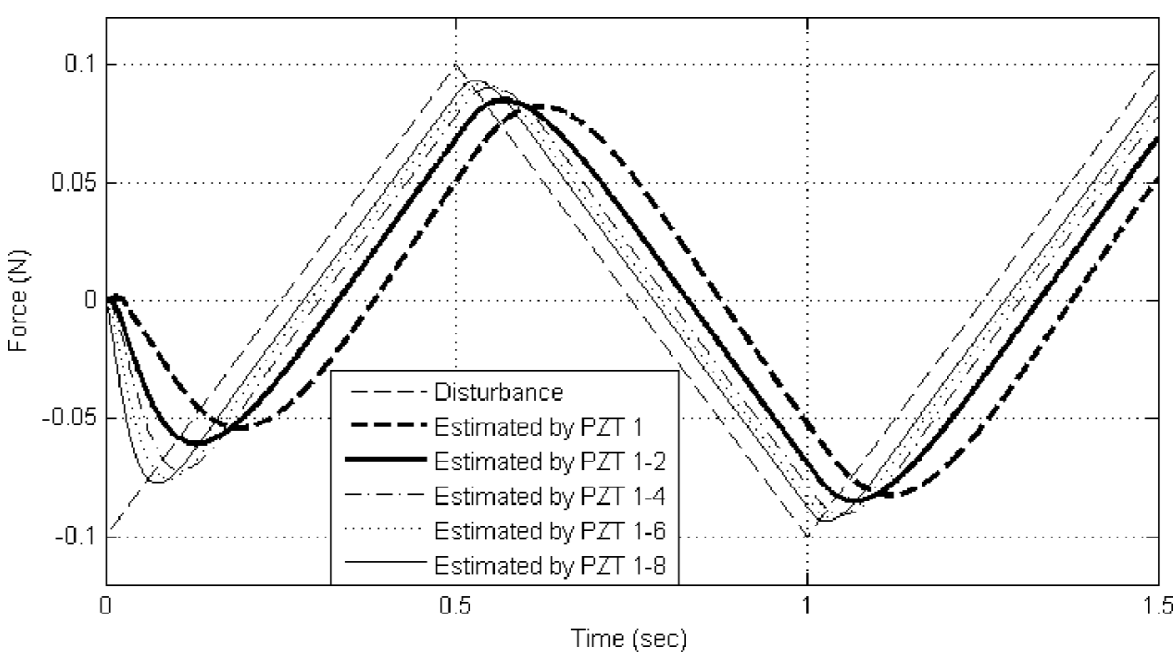

(b) Estimated disturbances

Fig. 9. Estimated triangle wave disturbances for the cantilevered beam using various numbers of piezoelectric sensors.

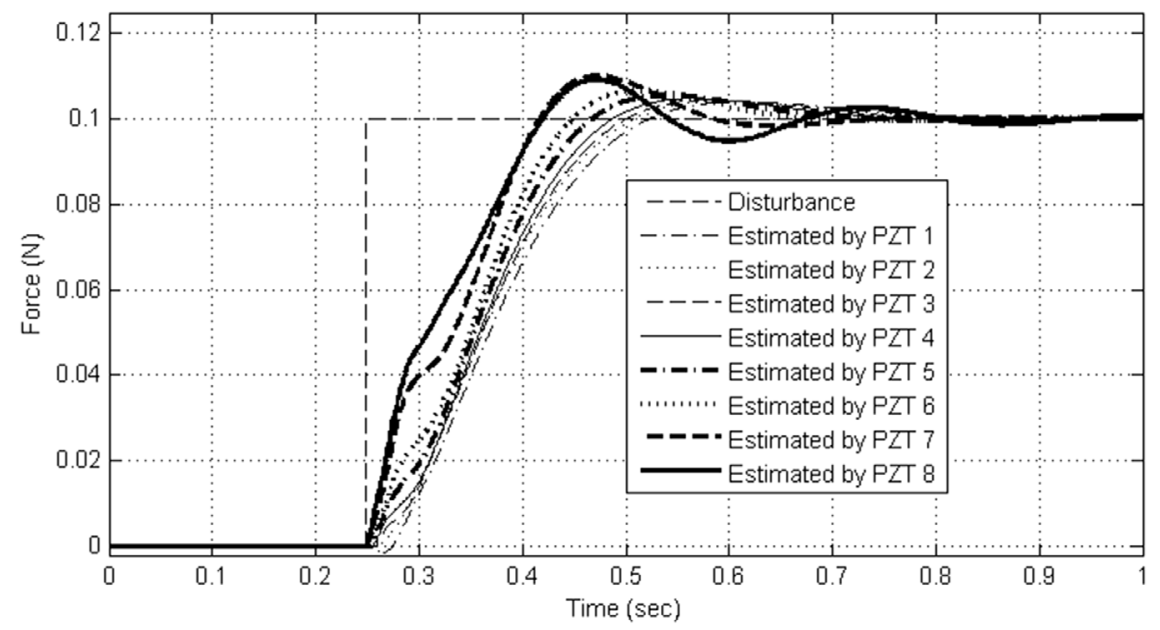

Fig. 10. Estimated step disturbances for the cantilevered beam with different positions of piezoelectric sensors. 
Table 6. The relative error of estimated disturbance with different position of piezoelectric sensors.

\begin{tabular}{llll}
\hline Sensor & \multicolumn{2}{c}{ The relative error $\varepsilon$} \\
\cline { 2 - 4 } & $\begin{array}{l}\text { Step disturbance } \\
\text { time 0-1 s }\end{array}$ & $\begin{array}{c}\text { Cosine disturbance } \\
\text { time } 0-1.5 \mathrm{~s}\end{array}$ & $\begin{array}{l}\text { Triangle wave disturbance } \\
\text { time 0-1.5 s }\end{array}$ \\
\hline PZT 1 & $1.10 \times 10^{-2}$ & $2.08 \times 10^{-2}$ & $2.09 \times 10^{-2}$ \\
PZT 2 & $1.06 \times 10^{-2}$ & $1.97 \times 10^{-2}$ & $1.99 \times 10^{-2}$ \\
PZT 3 & $1.05 \times 10^{-2}$ & $1.95 \times 10^{-2}$ & $1.96 \times 10^{-2}$ \\
PZT 4 & $1.03 \times 10^{-2}$ & $1.89 \times 10^{-2}$ & $1.90 \times 10^{-2}$ \\
PZT 5 & $0.99 \times 10^{-2}$ & $1.77 \times 10^{-2}$ & $1.79 \times 10^{-2}$ \\
PZT 6 & $0.94 \times 10^{-2}$ & $1.64 \times 10^{-2}$ & $1.66 \times 10^{-2}$ \\
PZT 7 & $0.82 \times 10^{-2}$ & $1.32 \times 10^{-2}$ & $1.36 \times 10^{-2}$ \\
PZT 8 & $0.74 \times 10^{-2}$ & $1.18 \times 10^{-2}$ & $1.23 \times 10^{-2}$ \\
\hline
\end{tabular}

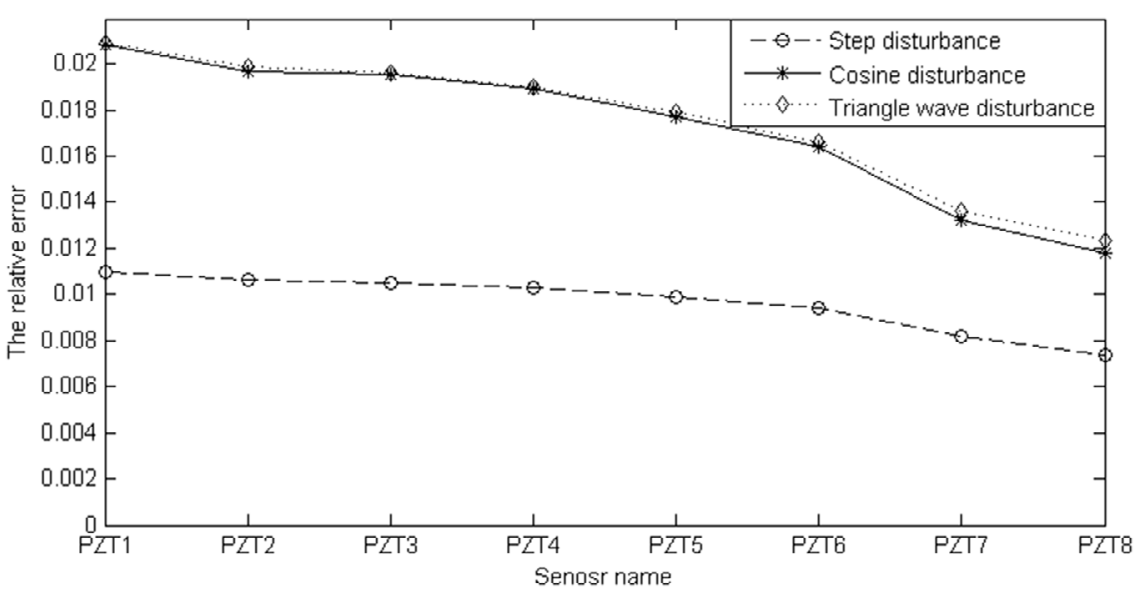

Fig. 11. The relative error of estimated disturbances for the cantilevered beam with different positions of piezoelectric sensors.

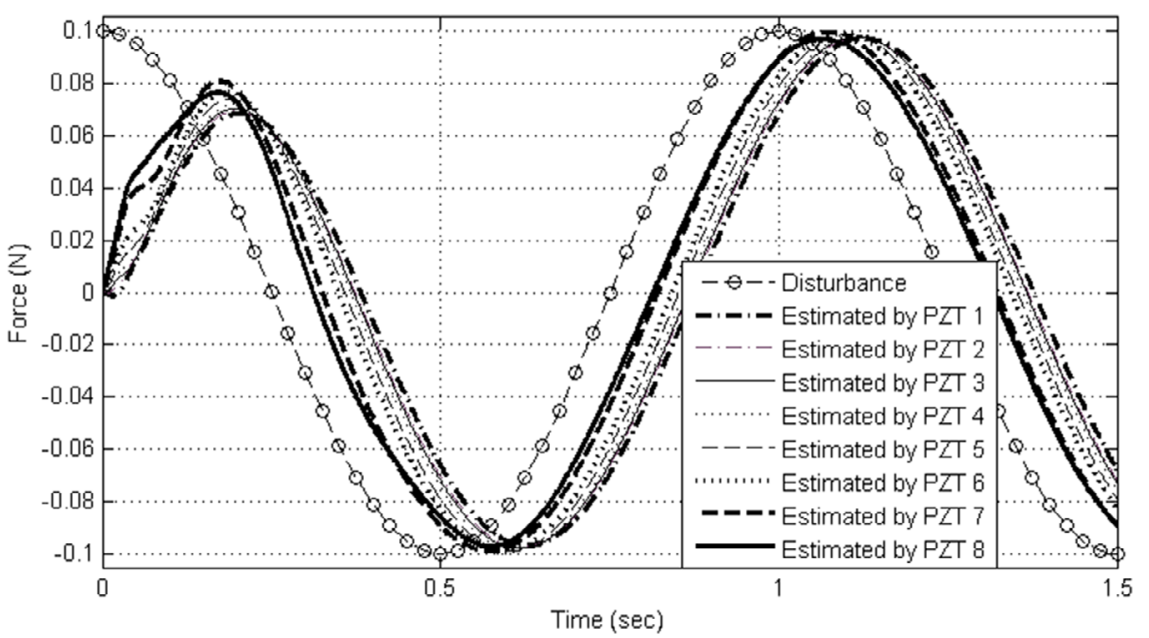

Fig. 12. Estimated cosine disturbances for the cantilevered beam with different positions of piezoelectric sensors.

piezoelectric sensors. Comparing the estimated disturbances by various numbers of piezoelectric sensors, it is obvious that increasing the number of piezoelectric sensors can smooth the estimation error and improve the dynamic performance of the disturbance estimation system. Moreover, the location of measurement points has an impact on the performance of disturbance estimation. 


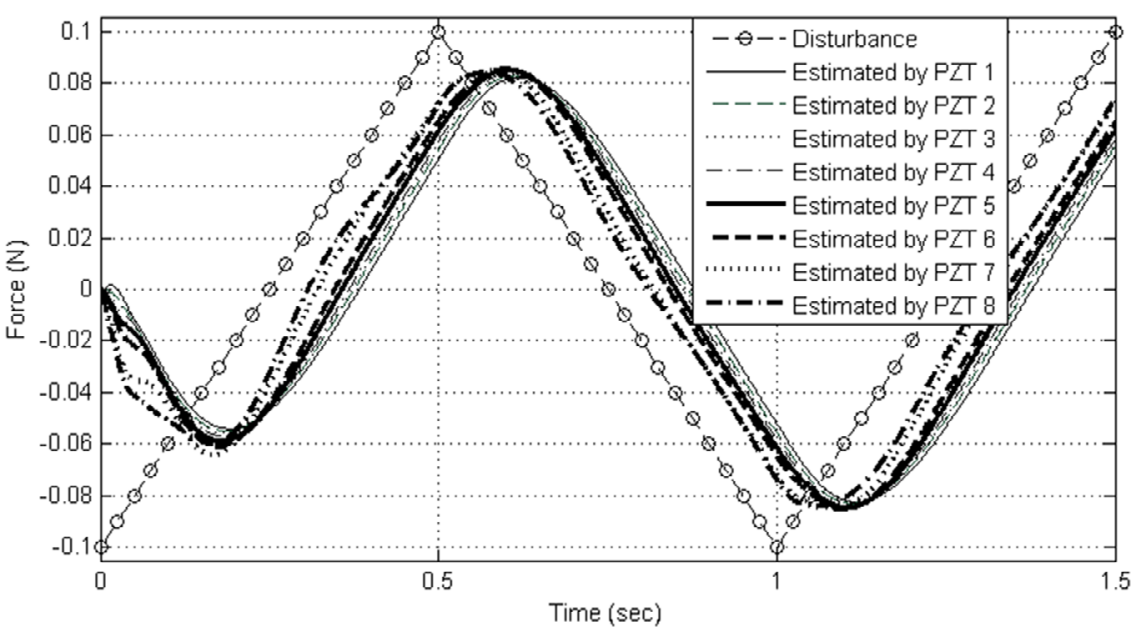

Fig. 13. Estimated triangle wave disturbances for the cantilevered beam with different positions of piezoelectric sensors.

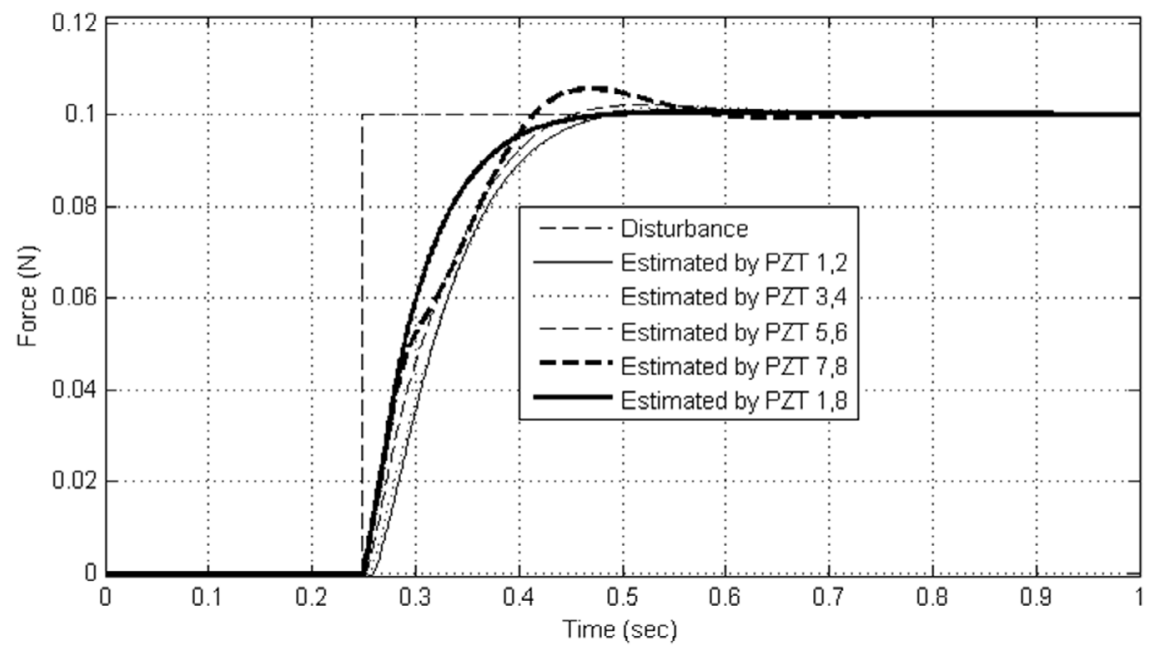

Fig. 14. Estimated step disturbance for the cantilevered beam by two piezoelectric sensors with different positions.

Acknowledgments. The authors gratefully acknowledge the support from the National Natural Science Foundation of China (Grant No. 11602193 and 51275413), the Opening Fund of State Key Laboratory of Structural Analysis for Industrial Equipment, Dalian University of Technology - China (Grant No. GZ15212), the Opening Fund of State Key Laboratory of Mechanics and Control of Mechanical Structures, Nanjing University of Aeronautics and Astronautics - China (Grant No. MCMS-0517G01), and the "111 project" of China (Grant No. B13044).

\section{References}

[1] Y. Liu, W. Steve Shepard Jr., An improved method for the reconstruction of a distributed force acting on a vibrating structure, J. Sound Vib. 291 (2006) 369-387

[2] Y. Jia, Z.C. Yang, N. Guo, L. Wang, Random dynamic load identification based on error analysis and weighted total least squares method, J. Sound Vib. 358 (2015) 111-123
[3] D. Ginoya, P.D. Shendge, S.B. Phadke, Delta-operatorbased extended disturbance observer and its applications, IEEE Trans. Ind. Electron. 62 (2015) 5815-5828

[4] Q. Leclère, F. Ablitzer, C. Pézerat, Practical implementation of the corrected force analysis technique to identify the structural parameter and load distributions, J. Sound Vib. 351 (2015) 106-118

[5] L. Yu, T.H.T. Chan, Moving force identification based on the frequency-time domain method, J. Sound Vib. 261 (2003) 329-349

[6] F.D. Barlett Jr., W.G. Flannelly, Model verification of force determination for measuring vibration loads, J. Am. Helicopter Soc. 19 (1979) 4-18

[7] B. Hillary, D.J. Ewins, The use of strain gauges in forces determination and frequency response function, in Proceeding of 2nd International Modal Analysis Conference, Florida, USA, 1984, pp. 27-634

[8] S.E.S. Karlsson, Identification of external structural loads from measured harmonic responses, J. Sound Vib. 196 (1996) $59-74$ 
[9] J. Liu, X.S. Sun, X. Han, C. Jiang, D.J. Yu, A novel computational inverse technique for load identification using the shape function method of moving least square fitting, Comput. Struct. 144 (2014) 127-137

[10] G. Desangheer, R. Snoeys, Indirect identification of excitation force by modal coordinate transformation, in Proceedings of the 3rd IMAC, Florida, USA, 1985, pp. 685-690

[11] H. Ory, H. Glaser, D. Holzdeppe, Quality of modal analysis and reconstruction of forcing functions based on measured output data, in Proceedings of the 4th International Modal Analysis Conference, Los Angeles, 1986, pp. 850-857

[12] E. Jacquelin, A. Bennani, P. Hamelin, Force reconstruction: analysis and regularization of a deconvolution problem, J. Sound Vib. 265 (2003) 81-107

[13] H. Inoue, K. Kishimoto, T. Shibuya, T. Koizumi, Estimation of impact load by inverse analysis: optimal transfer function for inverse analysis, JSME Int. J. 35 (1992) 420-427

[14] D.C. Kammer, Input force reconstruction using a time domain technique, ASME J. Vib. Acoust. 120 (1998) 868874

[15] P.C. Müller, Indirect measurement of nonlinear effects by state observers, in: W. Schiehlen (Ed.), Nonlinear Dynamics in Engineering Systems, IUTAM Symposium Springer, Berlin, 1990, pp. 205-215

[16] M. Hou, P.C. Muller, Design of observers for linear systems with unknown inputs, IEEE Trans. Automat. Control 37 (1992) 871-875

[17] D. Söffker, T.J. YU, P.C. Muller, State estimation of dynamical system with nonlinearities by using PI observer, Int. J. Syst. Sci. 26 (1995) 1571-1582

[18] I. Krajcin, D. Söffker, Model-based estimation of contact forces in rotating machines, in Proceedings of the 4th Symposium on Mathematical Modeling, Vienna University of Technology, Austria, February 2003

[19] I. Krajcin, D. Söffker, Diagnosis and Control of 3D Elastic Mechanical Structures, in Proceedings of the 12th SPIE Symposium on Smart Structures and Materials, San, Diego, CA, March 2005
[20] S.Q. Zhang, H.N. Li, R. Schmidt, P.C. Müller, Disturbance rejection control for vibration suppression of piezoelectric laminated thin-walled structures, J. Sound Vib. 333 (2014) $1209-1223$

[21] S.Q. Zhang, H.N. Li, R. Schmidt, P.C. Müller, X.S. Qin, Disturbance rejection control for vibration suppression of smart beam and plates under a high frequency excitation, J. Sound Vib. 353 (2015) 19-37

[22] M. Michu, A. Berry, P.H.P. Micheau, Bending near field compensation in the context of vibroacoustic, active control, Mechanics \& Industry 15 (2014) 551-555

[23] L. Rubbert, P. Renaud, S.C.J. Gangloff, Design of a compensation mechanism for an active cardiac stabilizer based on an assembly of planar compliant mechanisms, Mechanics \& Industry 15 (2014) 147-151

[24] S. Kerroumi, Dynamic classification method of fault indicators for bearings' monitoring, Mechanics \& Industry 14 (2013) 115-120

[25] S. Chesne, C. Pezerat, Distributed piezoelectric sensors for boundary force measurements in Euler-Bernoulli beams, Smart Mater. Struct. 20 (2011) 075009

[26] O. Katsuhiko, Discrete-Time Control Systems, 2nd Edition, Prentice Hall, Upper Saddle River, NJ, 1995

[27] M.S. Grewal, A.P. Andrews, Kalman Filtering Theory and Practice Using MATLAB, 4th Edition, John Wiley \& Sons, Inc., New York, 2014

[28] Y. Bar-Shalom, X. Rong Li, T. Kirubarajan, Estimation with Application to Tracking and Navigation: Theory Algorithms and Software, John Wiley \& Sons, Inc., New York, 2001

[29] S.Q. Zhang, R. Schmidt, X.S. Qin, Active vibration control of piezoelectric bonded smart structures using PID algorithm, Chin. J. Aeronaut. 28 (2015) 305-313

[30] S.Q. Zhang, Y.X. Li, R. Schmidt, Modeling and simulation of macro-fiber composite layered smart structures, Compos. Struct. 126 (2015) 89-100

[31] D.F. Gatz, L. Smith, The standard error of a weighted mean concentration bootstrapping vs other methods, Atmos. Environ. 29 (1995) 1185-1193

Cite this article as: B.-Y. Wu, X.-S. Qin, S.-Q. Zhang, J. Bai, T. Xue, R. Schmidt, Unknown disturbance estimation for vibration systems using distributed piezoelectric sensors, Mechanics \& Industry 19, 506 (2018) 